\title{
Perception of music-induced emotions in patients with somatoform disorders compared to healthy controls
}

Psychology of Music 2019, Vol. 47(4) 483-503 (C) The Author(s) 2018 Article reuse guidelines: sagepub.com/journals-permissions DOI: $10.1177 / 0305735618759819$

journals.sagepub.com/home/pom

\section{Carl Firle' (D), Martin Teufel2, Gunnar Blumenstock ${ }^{3}$, Robert Smolka 4 , Rebecca Erschens', Petra Windthorst', Stephan Zipfel' and Florian Junne'}

\begin{abstract}
Although music therapy has become a widespread approach used in the multimodal treatment of psychosomatic disorders, this is the first study investigating the perception of music-induced emotions (PoMIE) in patients with somatoform disorders. For the purposes of this study, $n=23$ patients (PG) with somatoform disorder (F45) were assessed for PoMIE within an experimental design. Additionally, $n=25$ healthy controls were included as a control group (CG) matched for age and gender. A questionnaire including the dimensional (valence, arousal) and the discrete (basic emotions) model were applied to assess PoMIE. At $\mathrm{t}_{0}$, the PG gave lower ratings of the emotion happiness, $F(1,48)=1.24, p<.01$, than the CG. Significantly higher ratings of fear were observed in the PG than in the CG. At $t_{1}$, the PG gave higher ratings of happiness for happy-targeted music stimuli than at $\mathrm{t}_{0}, t(22)=2.35, p<.05$. Higher ratings of fear in the PG compared to the CG also persisted after inpatient therapy, $t(46)=-2.48, p<.05$. The results suggest a lower perception of happiness and a higher perception of fear in the PG. A multimodal, inpatient therapy seems to influence the happiness perception of music-induced emotions in PG. The results may inform the further evaluation of music therapy interventions.
\end{abstract}

\section{Keywords}

anxiety, depression, emotion perception, music, psychosomatic medicine, somatoform disorders

\footnotetext{
${ }^{1}$ Department of Psychosomatic Medicine and Psychotherapy, Medical University Hospital Tuebingen, Tuebingen, Germany

${ }^{2}$ Department of Psychosomatic Medicine and Psychotherapy, LVR-Hospital Essen, University of Duisburg-Essen, Essen, Germany

${ }^{3}$ Institute for Clinical Epidemiology and Applied Biometry, University Hospital Tuebingen, University of Tuebingen, Tuebingen, Germany

${ }^{4}$ Wiegmann Klinik, Hospital for Psychosomatic Medicine and Psychotherapy, DRK Clinic Center Berlin, Berlin, Germany
}

\section{Corresponding author:}

Florian Junne, Medical University Hospital Tübingen, Osianderstr. 5, Tübingen, 72076, Germany.

Email: florian.junne@med.uni-tuebingen.de 
Music therapy is widely applied, especially in psychiatric and psychosomatic-medical treatment contexts. Aside from music therapy in the treatment of mental disorders, other clinical domains make use of music intervention: for example, in anesthesia, music is used experimentally as a co-therapeutic to reduce hypnotic agents (Koelsch et al., 2011; Matsota et al., 2013). In surgery, music is applied in post-operative recovery (Bernatzky, Presch, Anderson, \& Panksepp, 2011; Hole, Hirsch, Ball, \& Meads, 2015; van der Heijden, Oliai Araghi, van Dijk, Jeekel, \& Hunink, 2015), whereas in internal medicine, music shows positive effects on cardiovascular diseases (Bradt \& Dileo, 2009; Kunikullaya et al., 2015; Trappe, 2010). In oncology, music is applied during palliative treatment (Bradt, Dileo, Grocke, \& Magill, 2011). Furthermore, music becomes part of tinnitus therapy in otolaryngology (Argstatter, Krick, \& Bolay, 2008). Even if the effectiveness of music intervention is shown to be favorable on the treatment of somatic diseases in several studies, music has not as yet found clinical implications in the everyday lives of the non-psychiatric wards.

The main disciplines incorporating music in structured therapeutic approaches are the fields of psychosomatic medicine and psychiatry. Here, music therapy has become a widespread treatment component in the therapy of mental disorders along with art therapy (Junne \& Zipfel, 2016; Yinger \& Gooding, 2014), and its effectiveness has been shown (Kamioka et al., 2014). Patients with post-traumatic stress disorder and anxiety disorder benefit from music interventions, for example, concerning their symptom levels and sleep qualities (Blanaru et al., 2012; Carr et al., 2012; Castelino, Fisher, Hoskyns, Zeng, \& Waite, 2013; Jespersen \& Vuust, 2012; Petrovsky, Cacchione, \& George, 2015). Furthermore, cerebral activity during pain stimulus has been reported to be directly influenced by listening to music (Dobek, Beynon, Bosma, \& Stroman, 2014). Specific brain regions affected include the inferior frontal gyrus, the medial prefrontal cortex, the hypothalamus, the hippocampus and the supramarginal gyrus (Dobek et al., 2014; Koelsch, 2014, 2015). However, the causal effects and mechanisms of action of music-interventions are little understood to date. Additionally, indications and contraindications for specific entities have not been established yet (Gebhardt \& Georgi, 2007; Gebhardt \& von Georgi, 2015; Sondermann, 2002; Weymann, 1991). A biased emotional perception and a biased introspection ability of patients with mental disorders like depression and somatoform disorders has already been shown (Davidson, Pizzagalli, Nitschke, \& Putnam, 2002) for neuronal processing (Anand et al., 2005; Kalia, 2005; Rotenberg, 2008; Siegle, Steinhauer, Thase, Stenger, \& Carter, 2002), in perception of visual and auditive stimuli (Joormann, 2004; Kan, Mimura, Kamijima, \& Kawamura, 2004), in social communication (Gotlib, Krasnoperova, Yue, \& Joormann, 2004; Lim \& Kim, 2005; Suslow et al., 2004), and in psychodynamic assessments (Kernberg, 1980). Hence, it is of significant importance that the specific perception of musicinduced emotions be a focus of current research and explored considering the rising numbers of music therapy applications for patients with mental disorders (Wormit, Bardenheuer, \& Bolay, 2007; Wormit, Hillecke, Leins, Resch, \& Bardenheuer, 2007).

Studies investigating neuronal, vegetative, and psychological processes of music's effects are often investigated in healthy subjects (Janata, 2015; Koelsch, 2011, 2014; Koelsch \& Jäncke, 2015; Krumhansl, 1997; Lundqvist, Carlsson, Hilmersson, \& Juslin, 2008; Sarkamo, Tervaniemi, \& Huotilainen, 2013). Studies including patients with mental disorders are rare. With regard to neuronal representation, healthy individuals seem to process rather positively perceived music in the left frontal hemisphere (Altenmüller, Schurmann, Lim, \& Parlitz, 2002; L. A. Schmidt \& Trainor, 2001), as well as in the parahippocampal gyrus, ventral and dorsal striatum and anterior cingulate gyrus (Blood, Zatorre, Bermudez, \& Evans, 1999; Mitterschiffthaler, Fu, Dalton, Andrew, \& Williams, 2007). Negative or sad-perceived music seems to be processed in right anterior hemisphere (Altenmüller et al., 2002), limbic system 
(Koelsch, Fritz, von Cramon, Muller, \& Friederici, 2006), amygdala, hippocampal gyrus (Mitterschiffthaler et al., 2007), and orbitofrontal cortex and subcallosal cingulate (Blood et al., 1999). Psychophysiological studies point to a skin conductance response as a parameter of emotional arousal and emotional intensity during music presentation (Khalfa, Peretz, Blondin, \& Manon, 2002; Krumhansl, 1997; Rickard, 2004). Amplification of skin conductance thereby seems to be the highest during positive music stimuli (Khalfa et al., 2002; Lundqvist et al., 2008). Pulse rate correlates positively with happy and pleasant-perceived music (Orini et al., 2010; Salimpoor, Benovoy, Longo, Cooperstock, \& Zatorre, 2009) and also fear-targeted music stimuli (Etzel, Johnsen, Dickerson, Tranel, \& Adolphs, 2006; Krumhansl, 1997; Nyklícek, Thayer, \& Van Doornen, 1997).

Despite these findings focused on healthy persons, there are only a few studies analyzing the processing and perception of music in patients with mental disorders. Most of the existing studies assessed the response of patients diagnosed with depression. Punkanen and colleagues, for example, assessed the perception of music-induced emotions in 79 depressed patients and 30 healthy controls (Punkanen, Eerola, \& Erkkila, 2011). In accordance with preceding studies (Bodner et al., 2007; Naranjo et al., 2011), Punkanen et al. showed a negative-biased perception of music-induced emotions in depressed patients as compared to healthy controls expressed in lower happiness and higher anger and sadness ratings. Interestingly, patients with a bipolar disorder also seem to show a negative-biased perception of music during their euthymic phase (Choppin et al., 2016).

Given the high prevalence of somatoform disorders (Haller, Cramer, Lauche, \& Dobos, 2015) and the frequent use of music therapy in specialized treatment concepts (e.g., of psychosomatic medicine), an investigation into the effects of music on patients with somatoform disorders is urgently needed. The exploratory design of this study seeks to enable the formulation of hypotheses concerning the perception of music-induced emotions and psychophysiological reactions to music in patients with somatoform disorders. Furthermore, the secondary aim of this study is to explore the time stability of the findings in the patient and control groups. The patient group therefore passes a multimodal, psychosomatic inpatient treatment (treatment as usual) focusing on the symptoms of somatoform disorders. To the best of our knowledge, this is the first study investigating the differential emotional perception of specific music stimuli in patients with somatoform disorders compared to healthy controls in a cross-sectional design.

The primary aim of the study is to explore the perception of music-induced emotions in patients with somatoform disorders as compared to a healthy control group. As the secondary aim, time stability effects are analyzed for each of the groups (patients and healthy subjects) separately (uncontrolled) by a follow-up measurement in each group. Here, the study aims were to detect trends and changes of the perception of music-induced emotions of patients with somatoform disorders and in healthy subjects over time.

The exploratory research questions therefore are:

1. Does the perception of music-induced emotions in patients with somatoform disorders differ from healthy controls in cross-sectional comparison?

2. Do the psychophysiological reactions of patients with somatoform disorders to music differ from those of healthy controls?

3. Are there differences between subgroups (e.g. +/- alexithymia) within the cohort of patients with somatoform disorders concerning the perception of music-induced emotions?

4. Are the patterns of music perception in patients with somatoform disorders and in healthy subjects stable over time? 
Regarding research question 4 , it is important to note that this is purely an exploratory research question; hence, it was not hypothesized that the treatment as usual (TAU) patients receive during the time-stability interval changes the perception of music-induced emotions in any specific way.

\section{Methods}

\section{Study design}

The study was designed as an explorative, cross-sectional study with a time-stability followup measurement. In the cross-sectional study, the perception of the music-induced emotions of patients with somatoform disorders is compared to healthy controls. Furthermore, psychophysiological reactions to music, including the parameters of skin conductance response, heart rate, breath frequency, acral temperature and nuchal electromyographic activity, are assessed in both groups. In a follow-up measurement, the time-stability effects of the perception of music-induced emotions and psychophysiological reactions to music are detected: the patient group received inpatient TAU during the interval; the group of healthy subjects was measured four weeks after the first measurement without any specific intervention.

\section{Selection of participants}

All patients were recruited within the department of psychosomatic medicine at a tertiary university medical center in Germany. Healthy controls were recruited through public advertisements. Participants were asked to sign an informed-consent form before entering the study. The study was approved by the ethical board of the medical faculty and university clinic at Tübingen (618/2013BO2, 03.12.2013).

\section{Inclusion criteria}

Patient group. Twenty patients were intended for this explorative study. Patients had to meet the criteria of the ICD-10 for somatization disorder (F45.0), undifferentiated somatoform disorder (F45.1), or somatoform pain disorder (F45.4). Diagnoses were validated using ICD-10 symptom checklists within a structured interview (see below). Extensive chart review was conducted during the recruitment process to ensure that the inclusion criteria were met. The use of ICD-10 based diagnosis criteria applied in structured interviews was performed in keeping with the current research practices (Giel, Schag, Plewnia, \& Zipfel, 2013; Schag et al., 2013). Exclusion criteria were acute suicidality, schizophrenic disorders (F2), substance-related addiction, insufficient hearing ability and insufficient language skills. In accordance with current research practices (Giel et al., 2013; Schag et al., 2013), patients with mood-modulating or affect-influencing psychotropic medication, such as benzodiazepines or strong analgesics, including opioids or mood stabilizers like lithium or anticonvulsants (except for antidepressants), were not included in the study.

Control group. Twenty healthy subjects were planned for the control group. Healthy controls for the cross-sectional comparison were matched for age and gender relating to participants in the patient group. The follow-up $\left(\mathrm{t}_{1}\right)$ in both groups took place at least four weeks after the baseline measurement $\left(t_{0}\right)$. During this period, there was no intervention for the control group. 
Exclusion criteria were mental disorders, insufficient hearing ability and insufficient language skills. Participation in the two measurements was voluntary.

\section{Instruments}

A standardized interview, based on the German version of "Check Lists for International Diagnosis, ICD-10” (Hiller, 2005), was performed by the clinical examiner for depression and somatoform disorders. The evaluation led to the ICD-10 diagnosis, further validated by the results of the Patient Health Questionnaire (PHQ).

All questionnaires for participants were presented via the software Adobe Acrobat XI Pro on a 17-in diameter 4:3 Eizo $^{\circledR}$-LCD-Monitor. The font was Arial, the text size 12 pt. The distance between eye and monitor was about $1 \mathrm{~m}$.

In the following, the questionnaires, the instruments for the assessment of music-induced emotions and the multi-sensor system used for recording the psychophysiological variances are described.

The PHQ in the German version, translated and validated by Gräfe et al. (Gräfe, Zipfel, Herzog, \& Löwe, 2004), served as the clinical assessment of depression, somatoform syndrome, and stress syndrome. The original version was created by Spitzer and colleagues (Spitzer, Kroenke, Williams, \& and the Patient Health Questionnaire Primary Care Study, 1999). Sensitivity is reported with $95 \%$ specificity overall with $86 \%$ for major depression. Reliability for the major depression scale is indicated with $\alpha=0.88$ and for the somatization scale with $\alpha=$ 0.79. The cut-off scores for depression subgroups were set in accordance with the ICD-10 diagnosis based on interviews (see above): 0-5 none, 6-9 mild, 10-15 moderate, $>15$ severe. The PHQ-score served as a continuous parameter in the analysis of correlation concerning calculations with the factor "severity of disease."

Characteristics of potential alexithymia were assessed with the German version of the Toronto Alexithymia Scale (TAS; Kupfer, Brosig, \& Brähler, 2001). The original TAS evaluation showed an internal consistency of $\alpha=0.67-0.84$ with good construct and criterion validity (Taylor, Bagby, Ryan, \& Parker, 1990). The TAS consists of 26 items and assesses three subscales (difficulty describing feelings, difficulty identifying feelings, and external-orientated thinking). The cut-off score for criteria alexithymic was 54.

Demographic data were collected via the questionnaire, which also included items concerning music taste and musical skills. After music exposition was completed, the preference for and recognition of presented music was assessed via questionnaire.

Instruments used to assess the perception of music-induced emotions. The perception of musicinduced emotions was assessed using the dimensional and the discrete model of emotional perception. The dimensional model is based on Russell's circumplex model (Russell, 1980) and has been validated for the exploration of music-induced emotions (Bigand, Vieillard, Madurell, Marozeau, \& Dacquet, 2005; Eerola \& Vuoskoski, 2013; Schubert, 1999). The discrete model consists of the basic emotions and is commonly used for the assessment of emotions (Eerola \& Vuoskoski, 2013; Ekman, 1992; Juslin, Liljeström, Laukka, Västfjäll, \& Lundqvist, 2011). The participants in our study rated valence (pleasantness), arousal and basic emotions (happiness, sadness, fear, anger, surprise, and disgust) on visual analogue scales. The continuous visual analogue scales were scaled on $10 \mathrm{~cm}$ with 10 hidden increments; the valence and arousal scale ranged from -5 (unpleasant/low arousal) to +5 (pleasant/ high arousal) and the basic emotion scales ranged from 0 to 9 (no emotion-strong emotion). After the presentation of a music stimulus, each participant had to rate the dimensional and 


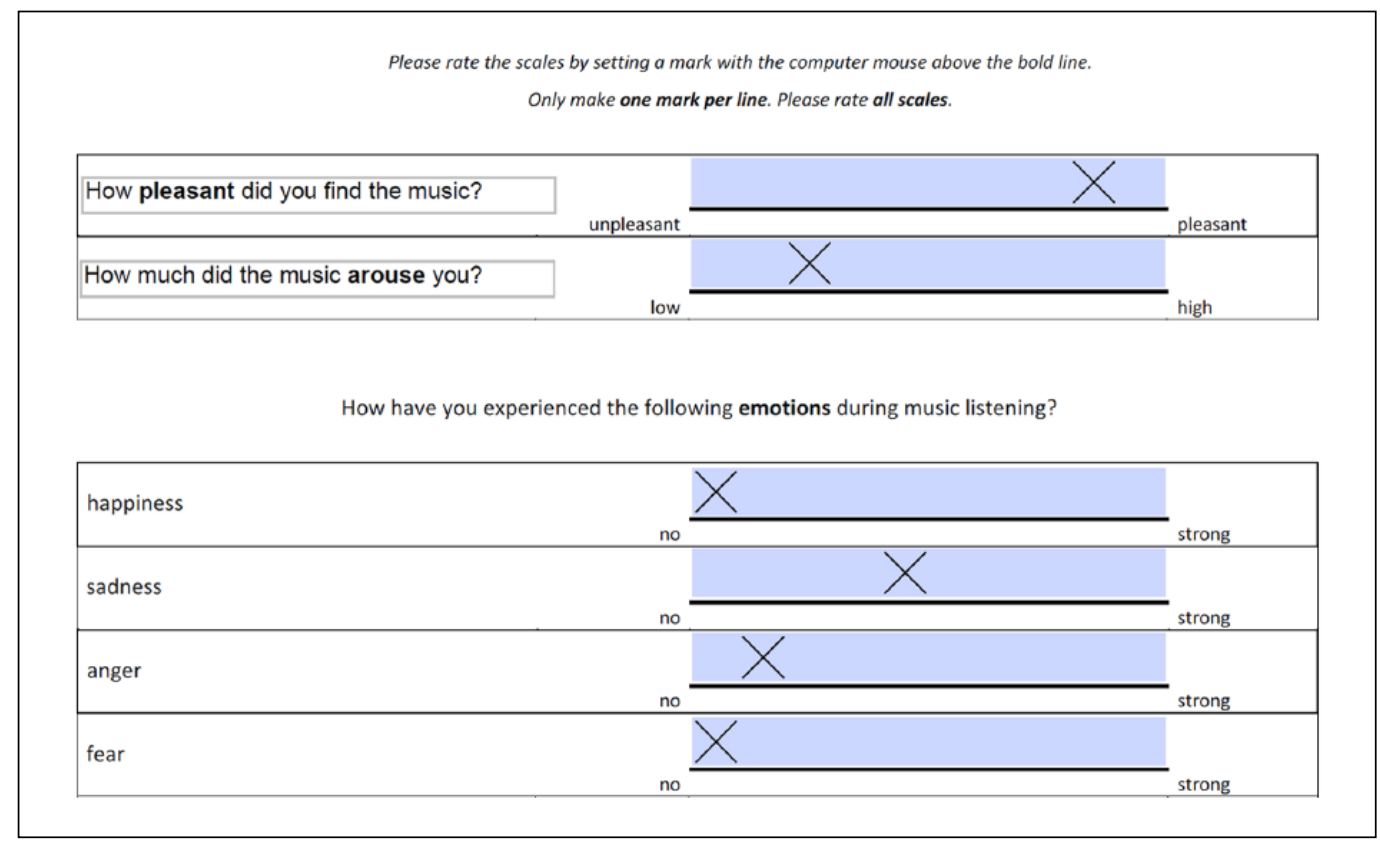

Figure I. Example extract from the questionnaire instrument of the assessment of the perception of music induced emotions (translated from German into English).

the discrete parameters on the digitally presented scales in consideration of the evoked feelings (see Figure 1).

Physiological measures. Physiological data were collected during the entire 29 minutes of music presentation and during the time between music stimuli when participants rated their perception on visual analogue scales. In this way, delayed psychophysiological reactions to music should also have been detected. The psychophysiological parameters included skin conductance response, acral temperature, pulse rate, breath frequency and muscle activity of nuchal muscles (electromyography). They were recorded using the physiosystem 7040c from Insight Instruments ${ }^{\mathbb{R}}$ and the software SoftMed (Fleming \& Ginter, 2006). The examiner was trained in the use of the EN (Euro Norm) certified biofeedback system recorder.

Physiosystem 7040c consists of a sensor plate including a combined module that detects skin conductance response, acral temperature, and pulse rate at the finger pad of the annular finger. Furthermore, it consists of an infrared breathing sensor that is installed on a stand in front of the abdomen and three changeable, one-time-use electrodes for electromyography (EMG) recording. For all parameters, a 5-minute baseline was recorded without music stimulus before each sequence of the experiment.

\section{Music stimuli}

The music stimuli included excerpts from classical music pieces, unfamiliar film soundtracks, and electronic music pieces. All music stimuli were rated and evaluated in an anonymous, online-based pilot study with 30 healthy volunteers using the above-described instruments for the assessment of the perception of music-induced emotions. Eight of 19 evaluated music 
Table I. The music stimulus materials and their characteristics assessed in an anonymous, online based pilot study with healthy persons. Each music stimulus had a length of approximately I min 30 seconds. Thirty people rated the music stimuli with the questionnaire of perception of music induced emotions (see also "Instruments") consisting of the dimensional (valence, arousal) and discrete (basic emotions) emotion model. Visual analogue scales went from $0=$ no emotion to $9=$ strong emotion for the discrete model, and from $-5=$ unpleasant/low arousal to $+5=$ pleasant/high arousal. The items of the different emotion models are reported in descending sequence of rating. Items with a rating $<1.5$ are not reported.

\begin{tabular}{|c|c|c|c|}
\hline Target emotion & Composer & Title & Rating results of the pilot study \\
\hline \multirow[t]{2}{*}{ Happiness } & $\begin{array}{l}\text { Bach, Johann } \\
\text { Christian }\end{array}$ & $\begin{array}{l}\text { Grand Overture } \\
\text { (Symphony), Op. 18, } \\
\text { No. 4, III Presto }\end{array}$ & $\begin{array}{l}\text { Happiness: } M=6.3, S D=2.68 \text {, } \\
\text { Valence: } M=2.5, S D=1.81 \\
\text { Arousal: } M=-1.1, S D=2.66\end{array}$ \\
\hline & $\begin{array}{l}\text { Mozart, Wolfgang } \\
\text { Amadeus }\end{array}$ & $\begin{array}{l}\text { Symphony No. } 8, \text { K. } 48 \text {, } \\
\text { IV Molto allegro }\end{array}$ & $\begin{array}{l}\text { Happiness: } M=6.0, S D=2.27 \text {, } \\
\text { Valence: } M=1.9, S D=1.71, \\
\text { Arousal: } M=-0.4, S D=2.30\end{array}$ \\
\hline \multirow[t]{2}{*}{ Sadness } & Klami, Uuno & Funeral March, Op. 8 & $\begin{array}{l}\text { Sadness: } M=4.2, S D=2.65, \\
\text { Happiness: } M=2.1, S D=2.29 \text {, } \\
\text { Valence: } M=0.4, S D=2.15, \\
\text { Arousal: } M=-2.1, S D=2.30\end{array}$ \\
\hline & $\begin{array}{l}\text { Hartmann, Karl } \\
\text { Amadeus }\end{array}$ & $\begin{array}{l}\text { Concerto funebre, I } \\
\text { Introduction - Largo }\end{array}$ & $\begin{array}{l}\text { Sadness: } M=4.3, S D=2.85, \\
\text { Happiness: } M=1.9, S D=2.38 \text {, } \\
\text { Valence: } M=0.7, S D=2.11, \\
\text { Arousal: } M=-3.1, S D=1.69\end{array}$ \\
\hline \multirow[t]{2}{*}{ Anger } & Splittercore & $\mathrm{N} / \mathrm{A}^{1}$ & $\begin{array}{l}\text { Anger: } M=5.5, S D=3.27 \\
\text { Fear: } M=2.0, S D=2.68, \\
\text { Valence: } M=-4.2, S D=1.48, \\
\text { Arousal: } M=0.6, S D=2.84\end{array}$ \\
\hline & Johansson, Ove & Coast, Stonecoast & $\begin{array}{l}\text { Anger: } M=4.5, S D=3.12, \\
\text { Fear: } M=2.1, S D=2.47 \\
\text { Valence: } M=-3.4, S D=1.95, \\
\text { Arousal: } M=0.7, S D=2.55\end{array}$ \\
\hline \multirow[t]{2}{*}{ Fear } & Cosma, Vladimir & $\begin{array}{l}\text { La Double vie de } \\
\text { Theophraste Longuet, Les } \\
\text { Catacombes de la mort }\end{array}$ & $\begin{array}{l}\text { Fear: } M=4.5, S D=2.81, \\
\text { Anger: } M=1.6, S D=1.90, \\
\text { Valence: } M=-3.9, S D=1.10, \\
\text { Arousal: } M=-0.3, S D=2.32\end{array}$ \\
\hline & Elfman, Danny & $\begin{array}{l}\text { Batman Returns, } \\
\text { opening Titles, from } \\
\text { Eerola \& Vuoskoski, } \\
2013\end{array}$ & $\begin{array}{l}\text { Fear: } M=5.1, S D=\text { N.A., } \\
\text { Anger: } M=3.0, S D=\text { N.A., } \\
\text { Sadness: } M=2.3, S D=\text { N/A, } \\
\text { Valence: } M=-0.7, S D=\text { N.A., } \\
\text { Arousal: } M=3.8, S D=\text { N.A. }\end{array}$ \\
\hline
\end{tabular}

I http://www.youtube.com/watch?v=AbmK7n0Koto.

stimuli were selected for the study based on their quality for eliciting the intended emotions (see Table 1). Reliability and validation (specificity and range of rating of emotion) thereby served as the selection criteria for these music samples. Two of the eight selected music stimuli (of 1 minute 30 seconds duration respectively) targeted one of the following emotions: happiness, sadness, fear, or anger. The music stimuli were presented in a semi-random order, consisting of eight sets of randomly sorted music stimuli. The sets were used in a continuous manner for the patient and control groups. All music stimuli were presented with $\mathrm{AKG}^{\circledR}$ k518le headphones (circa 150 grams). The maximum sound pressure level at the external ear was approximately $70 \mathrm{~dB}$. 


\section{Follow-up}

To assess the persistence of perception patterns with regard to music-induced emotions during inpatient treatment, the patient group was re-evaluated after at least four weeks of TAU (see below). The baseline $t_{0}$ was run before therapy, the follow-up $t_{1}$ directly afterwards. The group of healthy subjects were also measured twice, but received no specific interventionthus, the group of healthy subjects followed a natural time stability experiment. Throughout this article, $t_{0}$ represents the baseline (controlled) part of our study, and $t_{1}$ the follow-up that was designed to explore time stability and trends concerning the course of outcome parameters in both groups (patients and healthy subjects) separately (uncontrolled). All data were gathered at a tertiary University Hospital Centre in Germany. The laboratory conditions were controlled in relation to temperature $\left(21^{\circ} \mathrm{C}\right.$ on average), lighting (no direct sunlight) and noise (sound-protected room).

TAU. The TAU for the patient group consisted of a multimodal, psychosomatic inpatient therapy at a tertiary university hospital in the context of the Department for Psychosomatic Medicine and Psychotherapy at the University Hospital Centre in Tübingen. The treatment was administered in accordance with the German S3-Guidelines (Schaefert et al., 2012) for somatoform disorders containing: individual psychotherapy of 75 minutes per week (two sessions), group psychotherapy of 75 minutes per week (two sessions-one of 25 minutes, one of 50 minutes), creative therapies (music therapy, fine art) 100 minutes per week (two sessions of 50 minutes) and physiotherapy up to 3 hours per week. Primary nursing and educational therapy groups were offered on demand. The treatment was not standardized in the sense of a controlled intervention but rather focused on patient's individual requirements.

\section{Statistical analyses}

In accordance with previous studies (Fox, Knight, \& Zelinski, 1998; Naranjo et al., 2011; Punkanen et al., 2011), explorative and comparative analyses were conducted with variance analyses, parametric statistics and non-parametric models regarding differences between and within groups.

Visual analogue scales were transliterated corresponding to their increments ( 0 to 9 for discrete emotion scales, -5 to +5 for dimensional emotion scales). As shown in Figure 1, visual analogue scales were continuous with hidden increments. Thus, scales' value level was set on interval levels. The transliteration provided one scale-value for valence, arousal, and each of the basic emotions. The scale-value served as within-subject factor during ANOVA. The number of music stimuli was the level of repeated measurement ANOVA: eight levels for analysis concerning all music stimuli and two levels for analysis concerning only the music stimuli targeting a particular emotion. Groups or subgroups formed the between-subject-factor. ANCOVAs with the same setting were conducted with the factor "severity of disease" as covariance. The values for "severity of disease" were gathered as discussed within the methods section with presented questionnaires like PHQ-value or TAS-value. Post-hoc tests were done via the Tukey test (Schuckers, 2010).

Follow-up measurements were analyzed the same way. Furthermore, in order to detect the differences in the ratings of both groups, ANCOVAs were calculated: scale-value as a within-subject factor, number of music stimuli as level, group as between-subject factor, and scale-value of the first measurement as covariance. Including the values of the first 
measurement offers the opportunity to conduct a prospective analysis without statistical bias and with non-continuous factors (Vickers \& Altman, 2001). Furthermore, for followup $\left(\mathrm{t}_{1}\right)$ analyses, two-tailed $t$-tests were conducted for inner-group differences (paired). Correlations were ascertained with Pearson's $r$ on a significance level of 5\% (two-tailed) and $(n-2)$ degrees of freedom.

Physiological data were gathered as continuous measured values. For the parameters with high temporal frequency (skin conductance response, heart rate, and EMG activity) three 5-second intervals were calculated (15th-19th, 45th-49th and 78th-82nd second of each music stimulus). The mean value of the last 5 seconds of a free 5 -minute period at the beginning of the measurement served as the baseline/intervention free average. For the parameter with low temporal frequency and slow vegetative changes (acral temperature and breathing frequency), mean values for 10-second intervals were calculated for the second 73rd-82nd span of each music stimulus. The mean value of the last 10 seconds of the free 5-minute period served as the baseline/intervention-free average for the parameter's acral temperature and breathing frequency. ANCOVAs were conducted with the baseline average as covariance to reassure individual variability in psychophysiology reactions. Furthermore, relative values for the gathered intervals were calculated with the baseline average to conduct ANOVAs.

The mean values of the distinct psychophysiological parameters served as the within-subject factor, the group as the between-subject factor, and the intervals as the levels for the repeated measurement ANOVA. The evaluation of the psychophysiological data for follow-up measurement was performed as described above (Vickers \& Altman, 2001).

All reported results passed Levene's test for equality.

The software SPSS (v. 23) from IBM ${ }^{\circledR}$, JMP (v. 11) from SAS Institute ${ }^{\circledR}$, and Microsoft ${ }^{\circledR}$ Excel and Office (versions 2011 and 2016) were used for statistical analysis (Schuckers, 2010).

\section{Results}

\section{Sample characteristics}

Of all applicants, $n=25$ inpatients fulfilled the selection criteria for the baseline $\left(\mathrm{t}_{0}\right)$ of the study. Two patients from the twice-measured patient group had to be excluded due to an inpatient treatment shorter than 4 weeks. All $n=25$ healthy controls of the baseline $\left(\mathrm{t}_{0}\right)$ could participate in the follow-up. The demographic and sample characteristics for included patients and healthy controls are reported in Table 2 . None of the patients were taking psychotropic medication. Only one patient had a low dose Amitriptyline medication as antidepressant.

\section{Results of baseline measurements: Differences in the perception of music-induced emotions in patients with somatoform disorders as compared to healthy controls}

Patients with somatoform disorders showed significantly lower ratings of happiness than the control group. This was observed for the music stimuli with the target emotion of happiness, $F(1,48)=11.24, p<.01$ (compare Figure 5), as well as for all music stimuli, $F(1,48)=8.70$, $p<.01$. The decrease of happiness ratings thereby correlated with a decrease in valence rating for all music stimuli in the patient group $F(1,47)=12.27, p<.01$.

Concerning the ratings of fear, the patient group showed higher ratings than the control group for all music stimuli; however, the effect was not significant, $F(1,48)=3.83, p=.074$ (see also Figure 3). Significantly higher ratings of fear in the patient group as compared to the 


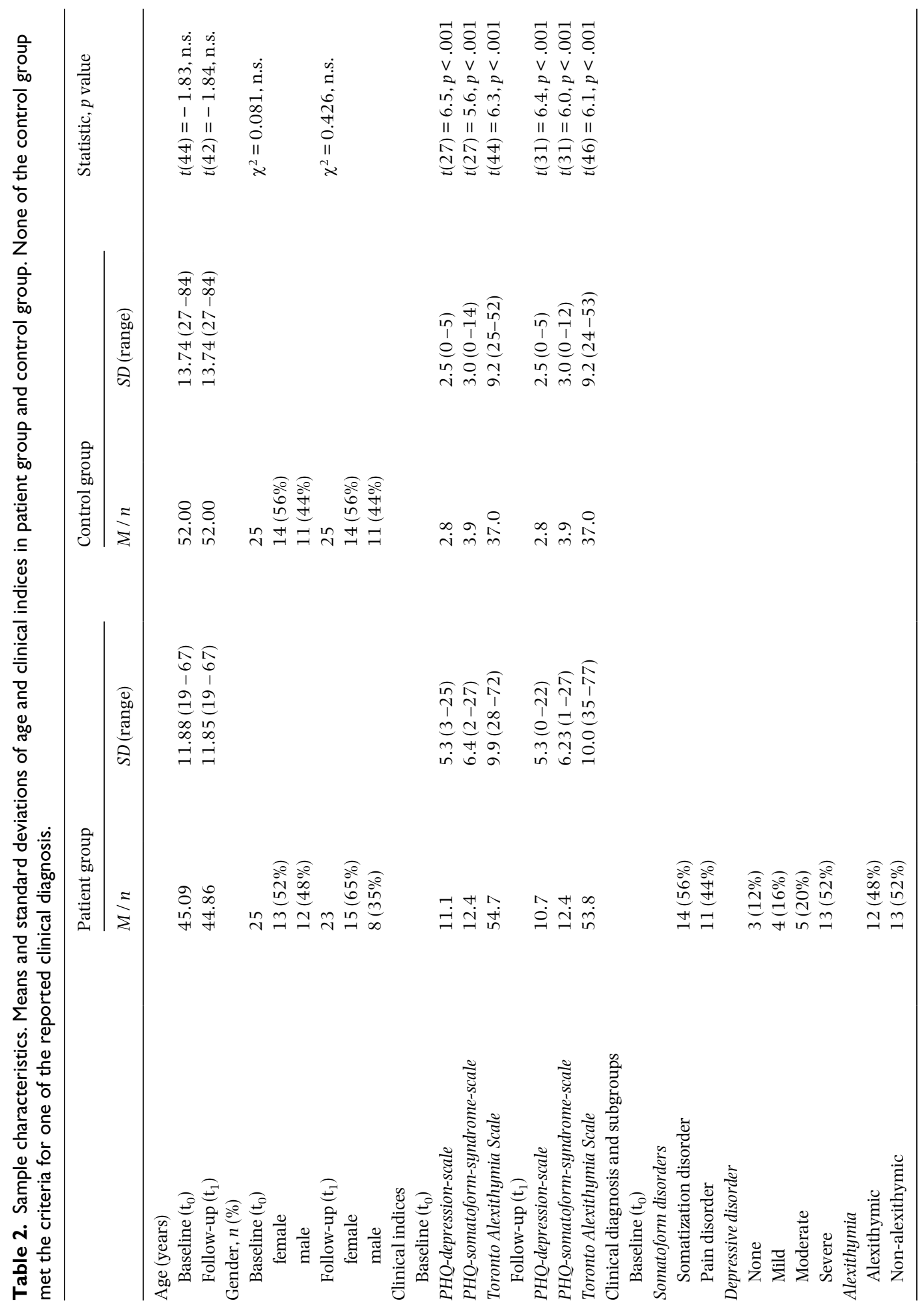




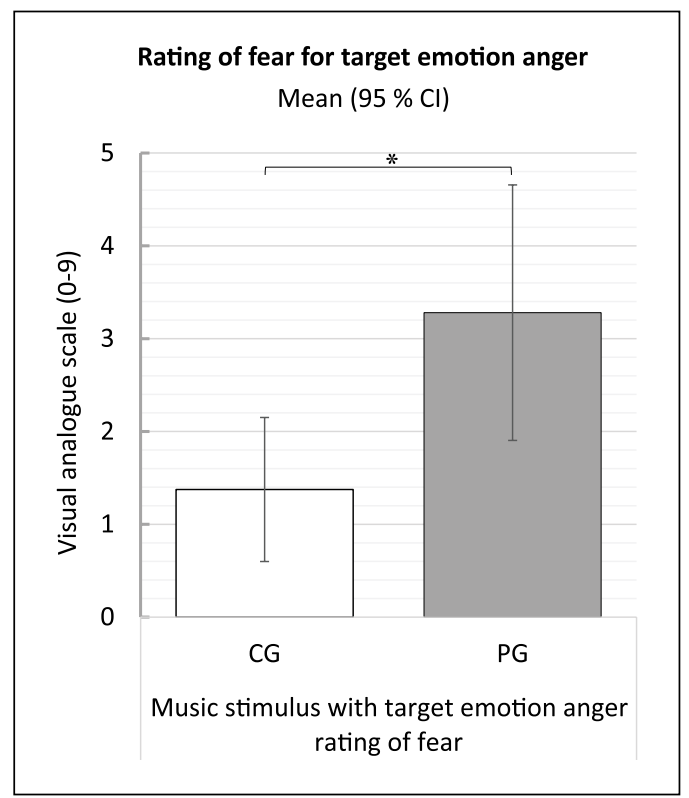

Figure 2. Rating of the experienced emotion fear during one of two music stimuli with target emotion anger, rated on a continuous visual analogue scale $(0=$ no emotion to $9=$ strong emotion). $P G=$ patient group, $\mathrm{CG}=$ control group, $\mathrm{Cl}=$ confidence interval.

control group were found for the two music stimuli with the target emotion sadness, $F(1,48)=$ $4.86, F(1,48)=4.14$, both $p<.05$, and for one of the two music stimuli with the target emotion anger, $F(1,48)=5,85, p<.05$ (see Figure 2 ).

Considering the type and the severity of the respective clinical state of the patient group, no significant differences could be observed between the clinical subgroups for emotion ratings. The somatization subgroup with an F45.1 diagnosis showed a trend of higher ratings for fear for all music stimuli, $F(2,45)=2.83, p=.07$. A Tukey post-hoc test showed differences between the somatization subgroup with higher ratings of fear and the pain disorder subgroup with lower ratings of fear, $p=.06$. Severity of depression correlated negatively with ratings of happiness for music stimuli with the target emotion happiness, $r(47)=-0.32, p<$ .05 , and for all music stimuli, $r(47)=-0.30, p<.05$. Severity of somatoform syndrome correlated positively with ratings of fear for the music stimuli with the target emotion fear, $r(47)$ $=0.30, p<.05$, and for all music stimuli, $r(47)=0.38, p<.01$ (see Figure 4 ). The same effect pertained to severity of depression, $r(48)=0.29, p<.05$, for music stimuli with the target emotion fear and, $r(50)=0.35, p<.05$, for the ratings of fear for all music stimuli. Paradoxically, the Alexithymia subgroup showed higher ratings of fear than the non-alexithymia subgroup, $F(1,48)=4.44, p<.05$ for all music stimuli and $F(1,48)=3.99, p=.051$ for music stimuli with the target emotion fear.

The psychophysiological measurements showed a significantly higher number of patients with a continuous relative increase in EMG activity of the nuchal muscles during one of the two music stimuli with the target emotion fear as compared to the number of healthy controls with the same psychophysiological alteration, $p=.005$, Fisher's exact test. Further analysis revealed no noticeable differences of psychophysiological reactions between the patient group and control group in the baseline measurements. 


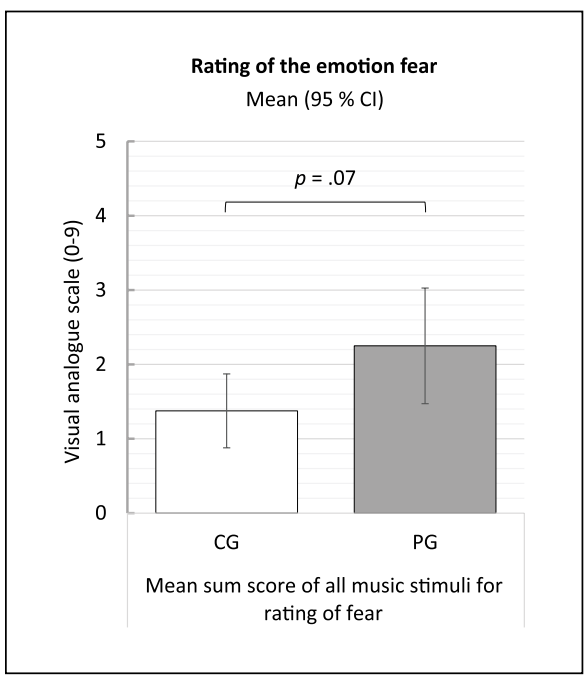

Figure 3. Rating of the experienced emotion fear for all music stimuli, rated on a continuous visual analogue scale $(0=$ no emotion to $9=$ strong emotion $)$. $P G=$ patient group, $C G=$ control group, $\mathrm{Cl}=$ confidence interval.

\section{Results of follow-up measurements: Time-stability (healthy subjects) and trends after TAU (patients)}

At $t_{1}$ (after at least four weeks of TAU), the patient group gave significantly higher ratings for happiness than at $\mathrm{t}_{0}$ (at admission to inpatient therapy). The effect was strong for the music stimuli with the target emotion happiness $t(22)=2.35, p<.05$ (see also Figure 5). The effect appeared between the change difference scores (see Figure 5) of ratings of happiness between the patient group and the control group as well, $t(46)=-1.98, p=.054$. The increase of happiness rating between the two measurements was observed in the patient group for all music stimuli, although not reaching the level of significance of $5 \%$, $t(22)=1.91, p=.07$.

Compared to the baseline, there were more patients with a continuous, relative pulse rate increase during one of the two music stimuli with the target emotion anger, Cramer's $V(23)=$ $0.61, p<.01$.

The somatization (F45.0) subgroup had more patients with a continuous relative increase in the EMG activity of the nuchal muscles during one of the two music stimuli with the target emotion fear than the other groups, $F(2,44)=3.98, p<.05$. A similar, not significant effect was observed for the somatization subgroup for one of the two music stimuli with the target emotion anger, $V(49)=0.41, p=.09, d=-0.33$.

\section{Further analysis}

For the controlled baseline-analyses, no gender differences in ratings of emotions could be assessed, nor were there differences in the ratings of emotions depending on the individual taste of music.

As expected, the analyses of the interrelation of somatoform disorders and depression revealed a strong, positive correlation, $r(47)=0.90, p<.001$. 


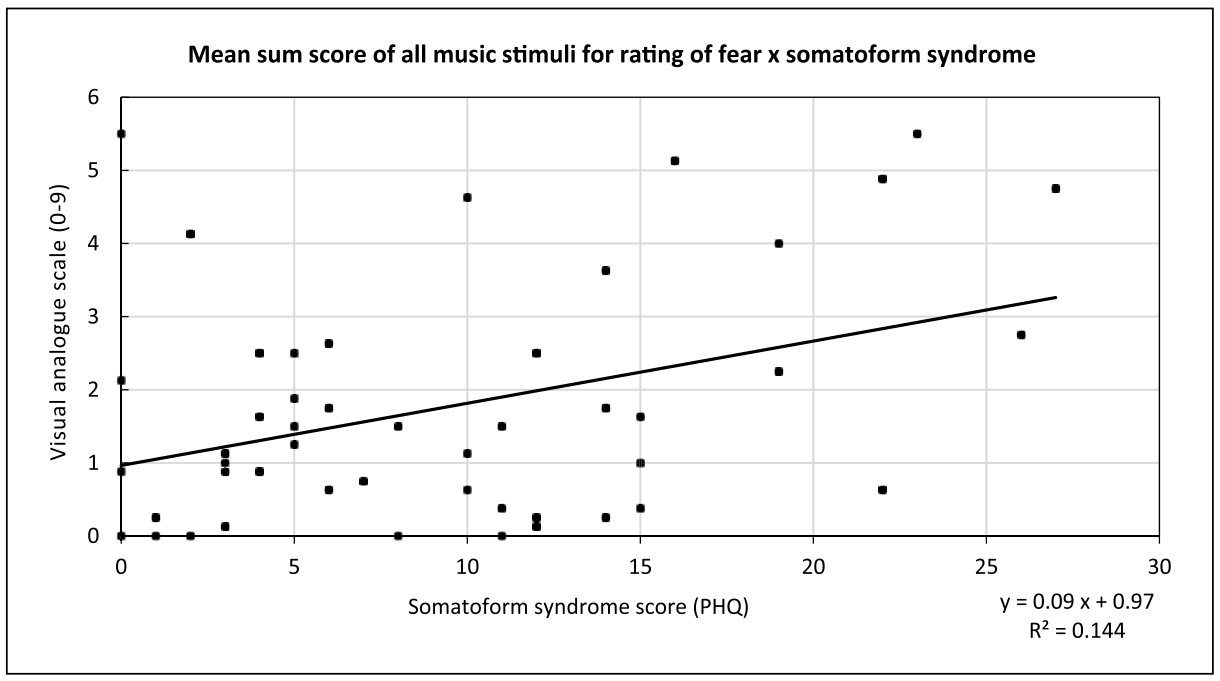

Figure 4. Correlation of the somatoform syndrome score of PHQ and the rating of fear for all music stimuli; rated on a continuous visual analogue scale $(0=$ no emotion to $9=$ strong emotion).

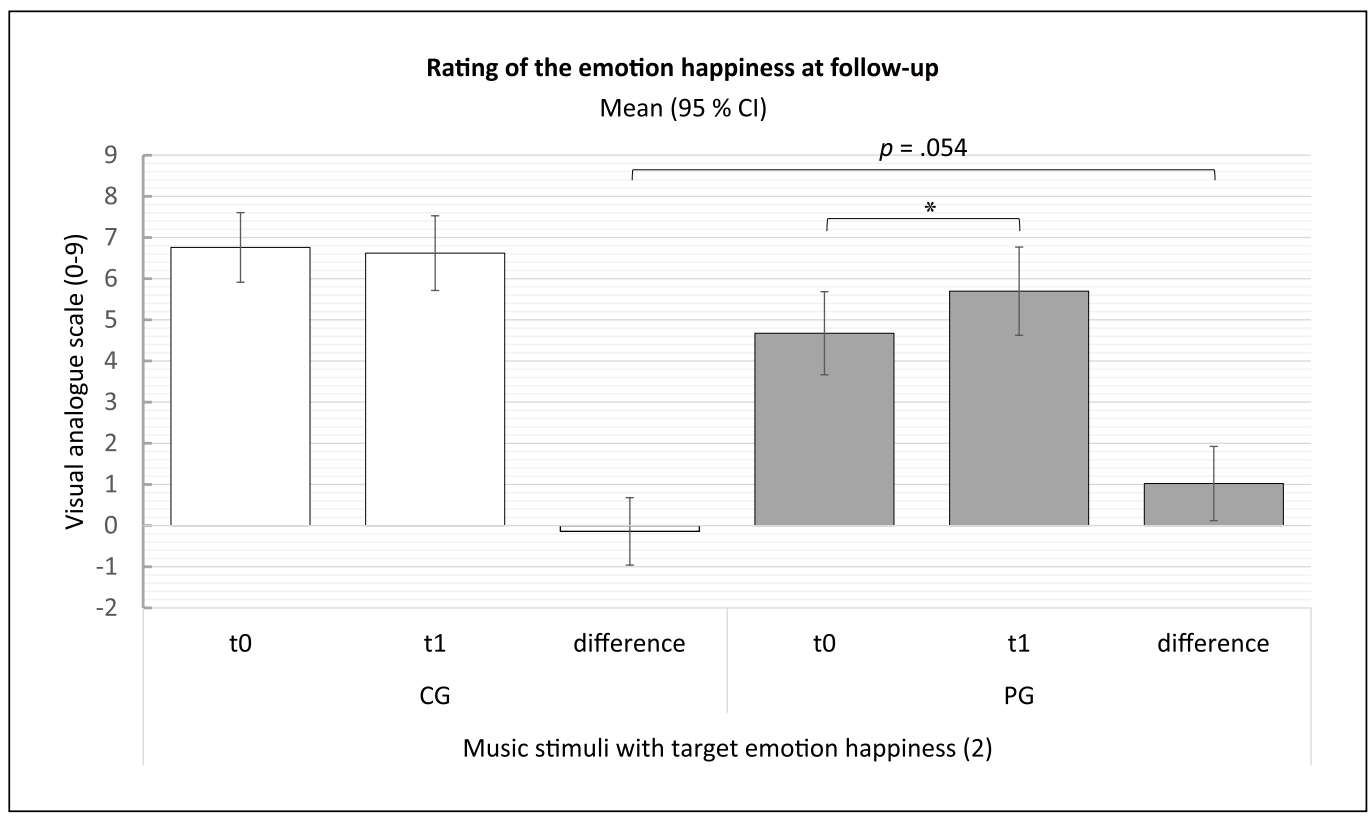

Figure 5. Rating of happiness for music stimuli with the target emotion happiness in the follow-up $\left(t_{1}\right) . P G=$ patient group, $C G=$ control group, $C l=$ confidence interval, $t_{0}=$ at the time of admission to inpatient therapy, $t_{1}=$ after at least 4 weeks of multimodal, psychosomatic inpatient therapy (PG) / after at least 4 weeks without intervention (CG).

At baseline, three (13\%) patients and three (14\%) healthy controls indicated familiarity with the music, but none could name title or composer. At the follow-up $\left(\mathrm{t}_{1}\right)$, four $(20 \%)$ patients and 
five $(20 \%)$ healthy controls indicated a familiarity with the music, whereas merely two persons recognized the music stimuli partially or completely from baseline measurement. Most of the participants (62-76\%) in the patient group and in the control group evaluated the music stimuli as partially conforming with their music taste.

\section{Discussion}

To the best of our knowledge, this is the first study investigating the perception of musicinduced emotions in patients with somatoform disorders as compared to healthy controls. The results show that patients with somatoform disorders seem to rate pleasant- and happy-targeted music stimuli in general as less "happy" and less pleasant than healthy controls did. Furthermore, the patient group showed higher ratings with regards to the target emotion fear in music generally and negative-targeted music stimuli than the control group (research question 1). Concerning the follow-up within group differences, explorative analyses show an increase in patients' rating of happiness. The ratings of fear at baseline $\left(\mathrm{t}_{0}\right)$ persisted in the patient group (research question 4). The clinical severity of somatoform syndrome correlated positively with the overall fear-ratings in the patient group (research question 3). Physiological arousal of the patient group was expressed by higher pulse rate and higher EMG activity of the nuchal muscles as compared to the baseline measurements while hearing anger-targeted music stimuli (research question 2). Patients with somatization disorders seemed to be more sensitive to this than patients with pain disorders.

\section{Interpretation}

Patients with somatoform disorders seem to feel less happiness while listening to music than healthy controls do. These findings can be seen to be in accordance with previous studies assessing the perception of music-induced emotions in patients with depression (Bodner et al., 2007; Naranjo et al., 2011; Punkanen et al., 2011). Previous studies revealed a systematic negative bias of depressed patients in music perception. Also, patients with bipolar disorder seem to show a negative bias in the perception of emotionally positive targeted music stimuli during the euthymic phase as compared to healthy controls (Choppin et al., 2016). The inability to develop a positive-affective judgement in patients with depression for previously heard melodies is described by Quoniam and colleagues (Quoniam et al., 2003). Obviously, the lower ratings for happiness can be explained as being one core symptom of depressive disorders. The majority of the here-investigated patient group showed comorbid symptoms of depression. Hence, the distinction between the effects of somatoform disorders and the influence of depressive symptoms on the happiness perception of music cannot be made on the basis of our current data. Future studies should control the investigation of patients with somatoform disorders (with high comorbidity rates of depression), for example by means of a study including patients who only manifest symptoms of depression.

A pain-specific result might be the increase in fear perception during specific music stimuli. Studies investigating patients with depression and their perception of music-induced emotions (Bodner et al., 2007; Naranjo et al., 2011; Punkanen et al., 2011) did not show any changes in fear perception. The latter studies described increased anger and sadness perception in music in depressed patients as compared to a control group. Despite a high prevalence of depression in our patient group, the ratings for sadness on the visual analogue scales did not differ between the two groups in any music stimuli. Concerning findings of severity of clinical state, our analysis showed a statistically high positive correlation between severity of somatoform syndrome 
and overall ratings of fear for all music stimuli. Previous studies described a correlation between the severity of depression and the rating of anger- and fear-targeted music (Naranjo et al., 2011; Punkanen et al., 2011).

The follow-up results of our study show an increase in happiness perception of music in the patient group which might be explained by an effect of the TAU during the time-stability interval. The follow-up results do not show a decline of fear perception in music in the patient group. This may be seen to be indicative of a relation to often persisting/slowly diminishing symptoms of pain during psychotherapeutic interventions.

Higher sympathetic nervous system activity and stress-induced answers of psychophysiology were observed during anger-targeted music sessions in the patient group than in the control group. The absence of physiological group differences at baseline $\left(t_{0}\right)$ seems unexpected and evades explanation at first. Given the absence of group differences of psychophysiological reactions, we tested the group differences at follow-up for exploratory reasons. Here, contrasts in the psychophysiological reaction between the two groups were found at $t_{1}$, which might be associated with the multimodal therapy patients received during the interval. This might lead to a hypothesis that, for example, a psychophysiological decoupling might exist at baseline and would be unset by TAU, eventually leading to a higher expression of psychophysiological answers. Previous studies on this topic could not be identified but, according to the literature available, a psychophysiological mismatch of patients with somatoform disorders is described in existing evidence (Evans et al., 2013; Pollatos et al., 2011; Rief \& Auer, 2001; J. E. Schmidt, Joyner, Carlson, \& Hooten, 2013). Therein, somatoform patients showed elevated sympathetic activity as compared to healthy controls.

Neuroimaging studies would be promising in this regard in order to detect changes in neuronal processing in patients with somatoform disorders and their perception of musicinduced emotions. Neuroimaging diagnostics were not included in this study, aiming to detect primary changes in the perception of music-induced emotions in patients with somatoform disorders. Different somatoform-disorder-specific neuronal areas were detected in earlier studies: the premotor and supplementary motor cortices, the middle frontal gyrus, the anterior cingulate cortex, the insula and the posterior cingulate cortex (Boeckle, Schrimpf, Liegl, \& Pieh, 2016). However, fMRI- and PET-based studies with music intervention seem not to have as yet been performed with patients with somatoform disorders. Those studies would be desirable to illuminate the appearance of the biased perception of music-induced emotions and biased psychophysiological reactions to music found in patients with somatoform disorders in this study.

\section{Limitations}

Due to the experimental and explorative design of the study, the sample size was kept low and interpretations of the data should be made with caution. This holds true especially for the subgroup analyses, which were performed to give first evidence regarding the perception of music-induced emotions of the different patient groups. However, the study was explicitly designed to generate hypotheses and to assess the feasibility and usability of the deployed instruments.

Another limitation may be seen in the fact that the comorbidity of symptoms of depression to some extent was present in the majority of the included patients who have somatoform disorders. Whilst this represents a naturalistic phenomenon (most patients with persisting somatoform disorders show some degree of depressive symptoms), a clear distinction of somatoform-specific and depressive-specific changes in the perception of music-induced emotions 
could therefore not be made on the basis of this study. For further studies, the separation of patients with somatoform disorders and patients with depression is strongly recommended. Thus, a three-armed study design with a somatoform patient group, a depression group and a healthy control group would be needed in future studies for advancements of our understanding in this respect.

Due to the exploratory design, the multimodal, psychosomatic inpatient therapy as TAU was not further specified and controlled. The intervention effects cannot be attributed to a certain treatment concept such as, for example, one-on-one psychotherapy or music therapy; they may even be pure effects of the natural course of the disease. Nevertheless, the follow-up study design alongside the multimodal treatment enables first insights into potential trends and important factors that have to be taken into account in future study designs on the matter.

\section{Conclusion}

This is the first study investigating the differential perception of music-induced emotions in patients with somatoform disorders as compared to a healthy control group, and their respective psychophysiological reactions to music. We found a decreased perception of happiness in the patient group for all presented music stimuli and for happy-targeted music stimuli. Furthermore, patients with somatization disorders and pain disorders seem to feel more fear in music than healthy controls. A pain-specific perception of music-induced emotions in the dimension of fear may therefore be hypothesized. Psychophysiological results may suggest a higher arousal level of patients with somatoform disorders towards stressful music as compared to controls. This explorative study gives suggestions for further studies seeking to illuminate the questions about the effects of music on therapeutic processes in the above groups of patients. Furthermore, we introduced instruments that may be helpful for fostering further progress in the scientific exploration of music therapy and related basic science.

\section{Acknowledgements}

We thank the nursing staff and the medical employees of the Department of Psychosomatic Medicine and Psychotherapy at the University of Tübingen, who contributed to the recruitment of patients. We honour Dietmar Matt for his dedicated mentoring in the use of the physiosystem. The authors thank further colleagues at the Institute for Clinical Epidemiology and Applied Biometry of University of Tübingen - especially Doris Guénon for her dedicated advice on data structure and analyses.

\section{Ethical approval}

Ethical approval for this project was given by the ethical board of medical faculty and university clinic Tübingen (ref. number 618/2013BO2, 03.12.2013).

\section{Funding}

The authors received no financial support for the research, authorship, and/or publication of this article.

\section{ORCID iD}

Carl Firle (iD) https://orcid.org/0000-0003-3233-178X

\section{References}

Altenmüller, E., Schurmann, K., Lim, V. K., \& Parlitz, D. (2002). Hits to the left, flops to the right: Different emotions during listening to music are reflected in cortical lateralisation patterns. Neuropsychologia, $40(13), 2242-2256$. 
Anand, A., Li, Y., Wang, Y., Wu, J., Gao, S., Bukhari, L., ... Lowe, M. J. (2005). Activity and connectivity of brain mood regulating circuit in depression: A functional magnetic resonance study. Biological Psychiatry, 57(10), 1079-1088. doi:10.1016/j.biopsych.2005.02.021

Argstatter, H., Krick, C., \& Bolay, H. V. (2008). Music therapy in chronic tonal tinnitus. Heidelberg model of evidence-based music therapy. HNO, 56(7), 678-685. doi:10.1007/s00106-008$1722-1$

Bernatzky, G., Presch, M., Anderson, M., \& Panksepp, J. (2011). Emotional foundations of music as a nonpharmacological pain management tool in modern medicine. Neuroscience \& Biobehavioral Reviews, 35(9), 1989-1999. doi:10.1016/j.neubiorev.2011.06.005

Bigand, E., Vieillard, S., Madurell, F., Marozeau, J., \& Dacquet, A. (2005). Multidimensional scaling of emotional responses to music: The effect of musical expertise and of the duration of the excerpts. Cognition \& Emotion, 19(8), 1113-1139. doi:10.1080/02699930500204250

Blanaru, M., Bloch, B., Vadas, L., Arnon, Z., Ziv, N., Kremer, I., \& Haimov, I. (2012). The effects of music relaxation and muscle relaxation techniques on sleep quality and emotional measures among individuals with posttraumatic stress disorder. Mental Illness, 4(2), 59-65. doi:10.4081/ mi.2012.e13

Blood, A. J., Zatorre, R. J., Bermudez, P., \& Evans, A. C. (1999). Emotional responses to pleasant and unpleasant music correlate with activity in paralimbic brain regions. Nature Neuroscience, 2(4), 382 387. doi:10.1038/7299

Bodner, E., Iancu, I., Gilboa, A., Sarel, A., Mazor, A., \& Dorit, A. (2007). Finding words for emotions: The reactions of patients with major depressive disorder towards various musical excerpts. The Arts in Psychotherapy, 34, 142-150.

Boeckle, M., Schrimpf, M., Liegl, G., \& Pieh, C. (2016). Neural correlates of somatoform disorders from a meta-analytic perspective on neuroimaging studies. NeuroImage: Clinical, 11, 606-613. doi:10.1016/j.nicl.2016.04.001

Bradt, J., \& Dileo, C. (2009). Music for stress and anxiety reduction in coronary heart disease patients. Cochrane Database of Systematic Reviews, 2, Cd006577. doi:10.1002/14651858.CD006577.pub2

Bradt, J., Dileo, C., Grocke, D., \& Magill, L. (2011). Music interventions for improving psychological and physical outcomes in cancer patients. Cochrane Database of Systematic Reviews, 8, Cd006911. doi:10.1002/14651858.CD006911.pub2

Carr, C., d'Ardenne, P., Sloboda, A., Scott, C., Wang, D., \& Priebe, S. (2012). Group music therapy for patients with persistent post-traumatic stress disorder: An exploratory randomized controlled trial with mixed methods evaluation. Psychology and Psychotherapy, 85(2), 179-202. doi:10.1111/ j.2044-8341.2011.02026.x

Castelino, A., Fisher, M., Hoskyns, S., Zeng, I., \& Waite, A. (2013). The effect of group music therapy on anxiety, depression and quality of life in older adults with psychiatric disorders. Australasian Psychiatry, 21(5), 506-507. doi:10.1177/1039856213492355

Choppin, S., Trost, W., Dondaine, T., Millet, B., Drapier, D., Verin, M., ... Grandjean, D. (2016). Alteration of complex negative emotions induced by music in euthymic patients with bipolar disorder. Journal of Affect Disorders, 191, 15-23. doi:10.1016/j.jad.2015.10.063

Davidson, R. J., Pizzagalli, D., Nitschke, J. B., \& Putnam, K. (2002). Depression: Perspectives from affective neuroscience. Annual Review of Psychology, 53, 545-574. doi:10.1146/annurev. psych.53.100901.135148

Dobek, C. E., Beynon, M. E., Bosma, R. L., \& Stroman, P. W. (2014). Music modulation of pain perception and pain-related activity in the brain, brain stem, and spinal cord: A functional magnetic resonance imaging study. Journal of Pain, 15(10), 1057-1068. doi:10.1016/j.jpain.2014.07.006

Eerola, T., \& Vuoskoski, J. K. (2013). A review of music and emotion studies: Approaches, emotion models, and stimuli. Music Perception, 30(3), 307-340.

Ekman, P. (1992). An argument for basic emotions. Cognition and Emotion, 6(3-4), 169-200. doi:10.1080/02699939208411068

Etzel, J. A., Johnsen, E. L., Dickerson, J., Tranel, D., \& Adolphs, R. (2006). Cardiovascular and respiratory responses during musical mood induction. International Journal of Psychophysiology, 61(1), 57-69. doi:10.1016/j.ijpsycho.2005.10.025 
Evans, S., Seidman, L. C., Tsao, J. C., Lung, K. C., Zeltzer, L. K., \& Naliboff, B. D. (2013). Heart rate variability as a biomarker for autonomic nervous system response differences between children with chronic pain and healthy control children. Journal of Pain, 6, 449-457. doi:10.2147/jpr.s43849

Fleming, D., \& Ginter, M. (2006). 3M to Acquire SoftMed Systems Inc., Health Information Management Solutions Provider. Retrieved from http://news.3m.com/press-release/company/3m-acquire-softmed-systems-inc-health-information-management-solutions-provide

Fox, L. S., Knight, B. G., \& Zelinski, E. M. (1998). Mood induction with older adults: A tool for investigating effects of depressed mood. Psychology and Aging, 13(3), 519-523.

Gebhardt, S., \& Georgi, R. (2007). Music, mental disorder and emotional reception behaviour. Music Therapy Today, 8(3), 419-445.

Gebhardt, S., \& von Georgi, R. (2015). The change of music preferences following the onset of a mental disorder. Mental Illness, 7(1), 21-25. doi:10.4081/mi.2015.5784

Giel, K. E., Schag, K., Plewnia, C., \& Zipfel, S. (2013). Antisaccadic training to improve impulsivity in binge eating disorder. European Eating Disorders Review, 21(6), 488-492. doi:10.1002/erv.2245

Gotlib, I. H., Krasnoperova, E., Yue, D. N., \& Joormann, J. (2004). Attentional biases for negative interpersonal stimuli in clinical depression. Journal of Abnormal Psychology, 113(1), 127-135. doi:10.1037/0021-843X.113.1.121

Gräfe, K., Zipfel, S., Herzog, W., \& Löwe, B. (2004). Screening psychischer Störungen mit dem "Gesundheitsfragebogen für Patienten (PHQ-D)." Diagnostica, 50(4), 171-181. doi:10.1026/00121924.50.4.171

Haller, H., Cramer, H., Lauche, R., \& Dobos, G. (2015). Somatoform disorders and medically unexplained symptoms in primary care. Deutsches Ärzteblatt International, 112(16), 279-287. doi:10.3238/ arztebl.2015.0279

Hiller, W. (2005). IDCL-Internationale Diagnosen-Checklisten für ICD-10 und DSM-IV Klinische Interviews und Ratingskalen (pp. 173-178). Göttingen: Hogrefe.

Hole, J., Hirsch, M., Ball, E., \& Meads, C. (2015). Music as an aid for postoperative recovery in adults: A systematic review and meta-analysis. The Lancet, 386(10004), 1659-1671. doi:dx.doi.org/10.1016/ S0140-6736(15)60169-6

Janata, P. (2015). Neural basis of music perception. Handbook of Clinical Neurology, 129, 187-205. doi:10.1016/B978-0-444-62630-1.00011-1

Jespersen, K. V., \& Vuust, P. (2012). The effect of relaxation music listening on sleep quality in traumatized refugees: A pilot study. Journal of Music Therapy, 49(2), 205-229.

Joormann, J. (2004). Attentional bias in dysphoria: The role of inhibitory processes. Cognition and Emotion, 18(1), 125-147. doi:10.1080/02699930244000480

Junne, F., \& Zipfel, S. (2016). The art of healing: Art therapy in the mental health realm. The Lancet Psychiatry, 3(11), 1006-1007. doi:10.1016/S2215-0366(16)30210-3

Juslin, P. N., Liljeström, S., Laukka, P., Västfjäll, D., \& Lundqvist, L.-O. (2011). Emotional reactions to music in a nationally representative sample of Swedish adults: Prevalence and causal influences. Musicae Scientiae, 15(2), 174-207. doi:10.1177/1029864911401169

Kalia, M. (2005). Neurobiological basis of depression: An update. Metabolism, $54(5$ Suppl 1), $24-27$. doi:10.1016/j.metabol.2005.01.009

Kamioka, H., Tsutani, K., Yamada, M., Park, H., Okuizumi, H., Tsuruoka, K., ...Mutoh, Y. (2014). Effectiveness of music therapy: A summary of systematic reviews based on randomized controlled trials of music interventions. Patient Preference and Adherence, 8, 727-754. doi:10.2147/PPA.S61340

Kan, Y., Mimura, M., Kamijima, K., \& Kawamura, M. (2004). Recognition of emotion from moving facial and prosodic stimuli in depressed patients. Journal of Neurology, Neurosurgery Eamp; Psychiatry, 75(12), 1667-1671. doi:10.1136/jnnp.2004.036079

Kernberg, O. F. (1980). Internal world and external reality: Object relations theory applied. New York, NY: Aronson.

Khalfa, S., Peretz, I., Blondin, J. P., \& Manon, R. (2002). Event-related skin conductance responses to musical emotions in humans. Neuroscience Letters, 328, 145-149. 
Koelsch, S. (2011). Toward a neural basis of music perception: A review and updated model. Frontiers in Psychology, 2, 110. doi:10.3389/fpsyg.2011.00110

Koelsch, S. (2014). Brain correlates of music-evoked emotions. Nature Reviews Neuroscience, 15(3), 170-180. doi:10.1038/nrn3666

Koelsch, S. (2015). Music-evoked emotions: Principles, brain correlates, and implications for therapy. Annals of the New York Academy of Sciences, 1337, 193-201. doi:10.1111/nyas.12684

Koelsch, S., Fritz, T., von Cramon, D. Y., Muller, K., \& Friederici, A. D. (2006). Investigating emotion with music: An fMRI study. Human Brain Mapping, 27(3), 239-250. doi:10.1002/hbm.20180

Koelsch, S., Fuermetz, J., Sack, U., Bauer, K., Hohenadel, M., Wiegel, M., . . Heinke, W. (2011). Effects of music listening on cortisol levels and propofol consumption during spinal anesthesia. Frontiers in Psychology, 2, 58. doi:10.3389/fpsyg.2011.00058

Koelsch, S., \& Jäncke, L. (2015). Music and the heart. European Heart Journal, 36(44), 3043-3049. doi:10.1093/eurheartj/ehv430

Krumhansl, C. L. (1997). An exploratory study of musical emotions and psychophysiology. Canadian Journal of Experimental Psychology, 51(4), 336-353.

Kunikullaya, K. U., Goturu, J., Muradi, V., Hukkeri, P. A., Kunnavil, R., Doreswamy, V., ... Murthy, N. S. (2015). Combination of music with lifestyle modification versus lifestyle modification alone on blood pressure reduction: A randomized controlled trial. Complementary Therapies in Clinical Practice. doi:10.1016/j.ctcp.2015.05.004

Kupfer, J., Brosig, B., \& Brähler, E. (2001). TAS-26: Toronto-Alexithymie-Skala-26 (Deutsche Version). Göttingen: Hogrefe.

Lim, S.-L., \& Kim, J.-H. (2005). Cognitive processing of emotional information in depression, panic, and somatoform disorder. Journal of Abnormal Psychology, 114(1), 50-61. doi:10.1037/0021843X.114.1.50

Lundqvist, L. O., Carlsson, F., Hilmersson, P., \& Juslin, P. N. (2008). Emotional responses to music: Experience, expression, and physiology. Psychology of Music, 37(1), 61-90. doi:10.1177/ 0305735607086048

Matsota, P., Christodoulopoulou, T., Smyrnioti, M. E., Pandazi, A., Kanellopoulos, I., Koursoumi, E., . . . Kostopanagiotou, G. (2013). Music's use for anesthesia and analgesia. Journal of Alternative and Complementary Medicine, 19(4), 298-307. doi:10.1089/acm.2010.0235

Mitterschiffthaler, M. T., Fu, C. H., Dalton, J. A., Andrew, C. M., \& Williams, S. C. (2007). A functional MRI study of happy and sad affective states induced by classical music. Human Brain Mapping, 28(11), 1150-1162. doi:10.1002/hbm.20337

Naranjo, C., Kornreich, C., Campanella, S., Noel, X., Vandriette, Y., Gillain, B., . . . Constant, E. (2011). Major depression is associated with impaired processing of emotion in music as well as in facial and vocal stimuli. Journal of Affective Disorders, 128(3), 243-251. doi:10.1016/j. jad.2010.06.039

Nyklícek, I., Thayer, J. F., \& Van Doornen, L. J. P. (1997). Cardiorespiratory differentiation of musicallyinduced emotions. Journal of Psychophysiology, 11, 304-321.

Orini, M., Bailon, R., Enk, R., Koelsch, S., Mainardi, L., \& Laguna, P. (2010). A method for continuously assessing the autonomic response to music-induced emotions through HRV analysis. Medical $\mathcal{E}$ Biological Engineering \& Computing, 48(5), 423-433. doi:10.1007/s11517-010-0592-3

Petrovsky, D., Cacchione, P. Z., \& George, M. (2015). Review of the effect of music interventions on symptoms of anxiety and depression in older adults with mild dementia. International Psychogeriatrics, 27(10), 1661-1670. doi:10.1017/s1041610215000393

Pollatos, O., Dietel, A., Herbert, B. M., Wankner, S., Wachsmuth, C., Henningsen, P., \& Sack, M. (2011). Blunted autonomic reactivity and increased pain tolerance in somatoform patients. Pain, 152(9), 2157-2164. doi:10.1016/j.pain.2011.05.024

Punkanen, M., Eerola, T., \& Erkkila, J. (2011). Biased emotional recognition in depression: perception of emotions in music by depressed patients. Journal of Affect Disorders, 130(1-2), 118-126. doi:10.1016/j.jad.2010.10.034 
Quoniam, N., Ergis, A. M., Fossati, P., Peretz, I., Samson, S., Sarazin, M., \& Allilaire, J. F. (2003). Implicit and explicit emotional memory for melodies in Alzheimer's disease and depression. Annals of the New York Academy of Sciences, 999, 381-384.

Rickard, N. S. (2004). Intense emotional responses to music: A test of the physiological arousal hypothesis. Psychology of Music, 32(4), 371-388. doi:10.1177/0305735604046096

Rief, W., \& Auer, C. (2001). Is somatization a habituation disorder? Physiological reactivity in somatization syndrome. Psychiatry Research, 101(1), 63-74.

Rotenberg, V. S. (2008). Functional brain asymmetry as a determinative factor in the treatment of depression: Theoretical implications. Progress in Neuro-Psychopharmacology and Biological Psychiatry, 32(8), 1772-1777. doi:https://doi.org/10.1016/j.pnpbp.2008.08.011

Russell, J. (1980). A circumplex model of affect. Journal of Personality and Social Psychology, 39(6), 11611178.

Salimpoor, V. N., Benovoy, M., Longo, G., Cooperstock, J. R., \& Zatorre, R. J. (2009). The rewarding aspects of music listening are related to degree of emotional arousal. PLoS One, 4(10), e7487. doi:10.1371/ journal.pone.0007487

Sarkamo, T., Tervaniemi, M., \& Huotilainen, M. (2013). Music perception and cognition: Development, neural basis, and rehabilitative use of music. Wiley Interdisciplinary Reviews: Cognitive Science, 4(4), 441-451. doi:10.1002/wcs.1237

Schaefert, R., Hausteiner-Wiehle, C., Hauser, W., Ronel, J., Herrmann, M., \& Henningsen, P. (2012). Nonspecific, functional, and somatoform bodily complaints. Deutsches Ärzteblatt International, 109(47), 803-813. doi:10.3238/arztebl.2012.0803

Schag, K., Teufel, M., Junne, F., Preissl, H., Hautzinger, M., Zipfel, S., \& Giel, K. E. (2013). Impulsivity in binge eating disorder: Food cues elicit increased reward responses and disinhibition. PLoS One, 8(10), e76542. doi:10.1371/journal.pone.0076542

Schmidt, J. E., Joyner, M. J., Carlson, C. R., \& Hooten, W. M. (2013). Cardiac autonomic function associated with treatment adherence after a brief intervention in patients with chronic pain. Applied Psychophysiology and Biofeedback, 38(3), 193-201. doi:10.1007/s10484-013-9222-9

Schmidt, L. A., \& Trainor, L.J. (2001). Frontal brain electrical activity (EEG) distinguishes valence and intensity of musical emotions. Cognition andEmotion, 15(4), 487-500. doi:10.1080/0269993004200187

Schubert, E. (1999). Measuring emotion continuously: Validity and reliability of the two-dimensional emotion-space. Australian Journal of Psychology, 51(3), 154-165. doi:10.1080/00049539908255353

Schuckers, M. (2010). Computational methods in biometric authentication. London, UK: Springer-Verlag.

Siegle, G. J., Steinhauer, S. R., Thase, M. E., Stenger, V. A., \& Carter, C. S. (2002). Can't shake that feeling: Event-related fMRI assessment of sustained amygdala activity in response to emotional information in depressed individuals. Biological Psychiatry, 51(9), 693-707. doi:10.1016/S00063223(02)01314-8

Sondermann, D. (2002). Musiktherapie. Stuttgart: Ahrens, S.; Schneider, W.

Spitzer, R. L., Kroenke, K., Williams, J. W., \& and the Patient Health Questionnaire Primary Care Study, G. (1999). Validation and utility of a self-report version of prime-md: The phq primary care study. Journal of the American Medical Association, 282(18), 1737-1744. doi:10.1001/jama.282.18.1737

Suslow, T., Dannlowski, U., Lalee-Mentzel, J., Donges, U.-S., Arolt, V., \& Kersting, A. (2004) Spatial processing of facial emotion in patients with unipolar depression: A longitudinal study. Journal of Affective Disorders, 83(1), 59-63. doi:10.1016/j.jad.2004.03.003

Taylor, G. J., Bagby, R. M., Ryan, D. P., \& Parker, J. D. A. (1990). Validation of the alexithymia construct: A measurement-based approach. Canadian Journal of Psychiatry, 35, 290-296.

Trappe, H. J. (2010). The effects of music on the cardiovascular system and cardiovascular health. Heart, 96(23), 1868-1871. doi:10.1136/hrt.2010.209858

van der Heijden, M. J., Oliai Araghi, S., van Dijk, M., Jeekel, J., \& Hunink, M. G. (2015). The effects of perioperative music interventions in pediatric surgery: A systematic review and meta-analysis of randomized controlled trials. PLoS One, 1O(8), e0133608. doi:10.1371/journal.pone.0133608

Vickers, A. J., \& Altman, D. G. (2001). Statistics notes: Analysing controlled trials with baseline and follow up measurements. BMJ, 323(7321), 1123-1124. 
Weymann, E. (1991). “... das ist ein weites Feld” - einige unordentliche Anmerkungen zur Praxis der Indikationsstellung für Musiktherapie in der psychotherapeutischen Klinik. Musiktherapeutische Umschau, 12, 170-180.

Wormit, A. F., Bardenheuer, H. J., \& Bolay, H. V. (2007). Aktueller Stand der Musiktherapie in Deutschland. Verhaltenstherapie \& Verhaltensmedizin, 28, 10-22.

Wormit, A. F., Hillecke, T. K., Leins, A. K., Resch, F., \& Bardenheuer, H. J. (2007). Musiktherapie bei chronischen, nicht-malignen Schmerzen. Verhaltenstherapie \& Verhaltensmedizin, 28(1), 100-114.

Yinger, O. S., \& Gooding, L. (2014). Music therapy and music medicine for children and adolescents. Child $\mathcal{E}$ Adolescent Psychiatric Clinics of North America, 23(3), 535-553. doi:10.1016/j.chc.2013.03.003 


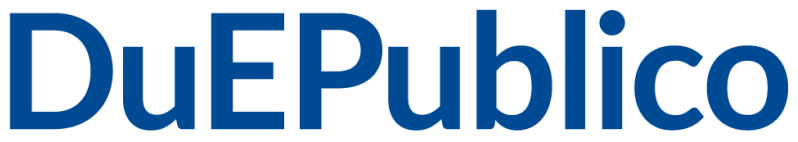

Duisburg-Essen Publications online offen im Denken

$\mathbf{U b} \mid$\begin{tabular}{l|l} 
universitäts \\
bibliothek
\end{tabular}

This text is made available via DuEPublico, the institutional repository of the University of Duisburg-Essen. This version may eventually differ from another version distributed by a commercial publisher.

DOI: $\quad 10.1177 / 0305735618759819$

URN: urn:nbn:de:hbz:464-20210503-111836-8

Firle, C. et.al.(2019). Perception of music-induced emotions in patients with somatoform disorders compared to healthy controls. Psychology of Music, 47(4), 483-503. https://doi.org/10.1177/0305735618759819

This publication is with permission of the rights owner freely accessible due to an Alliance licence and a national licence (funded by the DFG, German Research Foundation) respectively.

(C) The Author(s) 2018. All rights reserved. 